\title{
The Australian Water Resource Assessment Modelling System (AWRA)
}

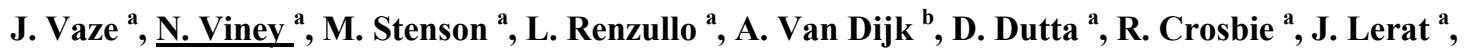 \\ D. Penton ${ }^{a}$, J. Vleeshouwer ${ }^{\text {a }}$, L. Peeters ${ }^{\text {a }}$, J. Teng, S. Kim ${ }^{\text {a }}$, J. Hughes ${ }^{\text {a }}$, W. Dawes ${ }^{\text {, }}$, Y. Zhang ${ }^{\text {, }}$, \\ B. Leighton ${ }^{\text {a }}$, J-M. Perraud ${ }^{\text {a }}$, K. Joehnk ${ }^{\text {a }}$, A. Yang ${ }^{\text {, }}$, B. Wang ${ }^{\text {, }}$, A. Frost ${ }^{\text {c }}$, A. Elmahdi ${ }^{\text {c }}$, A. Smith ${ }^{\text {, }}$, \\ C. Daamen ${ }^{c}$ \\ ${ }^{a}$ Water for a Healthy Country Flagship, CSIRO, Australia \\ ${ }^{b}$ Australian National University, Canberra, Australia \\ ${ }^{c}$ Bureau of Meteorology, Australia \\ Email: $\underline{\text { Jai.Vaze@csiro.au }}$
}

\begin{abstract}
The Australian Water Resource Assessment (AWRA) modelling system has been in development since 2008 to enable the Bureau of Meteorology to meet its legislated role in providing an annual National Water Account and a regular Australian Water Resource Assessment Report. The system uses available observations and an integrated landscape-groundwater-river water balance model to estimate the stores and fluxes of the water balance required for reporting. AWRA constitutes a unique example of implementing a coupled landscape, groundwater and regulated river system model at a continental scale and rolled out at high priority regions (National Water Account (NWA) regions).
\end{abstract}

The results for AWRA-L (landscape) implementation across 607 gauged catchments show that in both calibration and validation, the model typically provides streamflow predictions that are similar to those from other widely used conceptual hydrological models. The AWRA-R (river) model includes newly developed components for floodplain inundation modelling, accounting for irrigation diversions and groundwater surface water interactions. The results show that the model performs extremely well in majority of the modelling regions and it provides all the water fluxes and stores required for NWA.

The software architecture developed as part of AWRA integrates the individual components in a seamless manner with transfer of fluxes between the components at a daily time step for operational implementation. The system is fully functional on the Bureau's operating system and used for supporting the production of AWRA and NWA reports. The Bureau has used the AWRA modelling system to undertake water resource assessments across the country and already published one Water Resource Assessment (2010) and two National Water Accounts $(2010,2011)$. There has been a steady and continuous improvement in the AWRA model performance and the Bureau is currently undertaking the next round of Water Resource Assessments (2012) and a National Water Account (2012) using the current version of the AWRA system. It is anticipated that what-if scenario modelling and forecasting water resource availability will eventually come into scope in the next three years when the retrospective components of the system are fully implemented and operating efficiently and effectively.

Keywords: AWRA, water resource assessment, landscape modelling, surface water - groundwater interactions, river system modelling 


\section{INTRODUCTION}

In response to multiple concomitant pressures on Australia's water resources, the Australian Government, through the Commonwealth Water Act 2007, has given the Australian Bureau of Meteorology, responsibility for compiling and delivering comprehensive water information across the water sector. To fulfill its legislative responsibilities, the Bureau requires a water balance modelling system developed using state-ofthe-art hydrological science and computing technology that quantifies water flux and storage terms and their respective uncertainties (where applicable and possible) using a combination of data sets (on-ground metering, remotely sensed data and model outputs). The system need to be applicable across the continent and it should be flexible enough to be able to use all available data sources (when modelling data rich and data limited regions) with the most appropriate modelling techniques and tools suitable for use with the available data to provide nationally consistent and robust estimates. The outputs from the water balance modelling system are used to underpin a range of water information products delivered by the Bureau and thus the system needs to generate all the necessary water flux and storage terms at a spatial and temporal scale appropriate for aggregated reporting.

To achieve these objectives, in 2008, the Bureau and CSIRO through the Water for a Healthy Country National Research Flagship agreed to collaborate on research activities in the field of water information, to assist the Bureau develop a number of these new core roles. This collaboration was formalised through the Water Information Research and Development Alliance (WIRADA), which is now in its sixth year of operation.

A significant research and development effort in WIRADA is directed towards developing improved capability in water resource accounting and assessment. In the first 5 years of WIRADA, the Australian Water Resource Assessment (AWRA) modelling system was developed through three core components, together representing the Australian terrestrial water cycle. The model components represent processes between the atmosphere and the landscape (AWRA-L), in gauged rivers (AWRA-R) and in groundwater (AWRA-G), including all major water storages and fluxes in and between these components. Significant effort has been dedicated towards use of

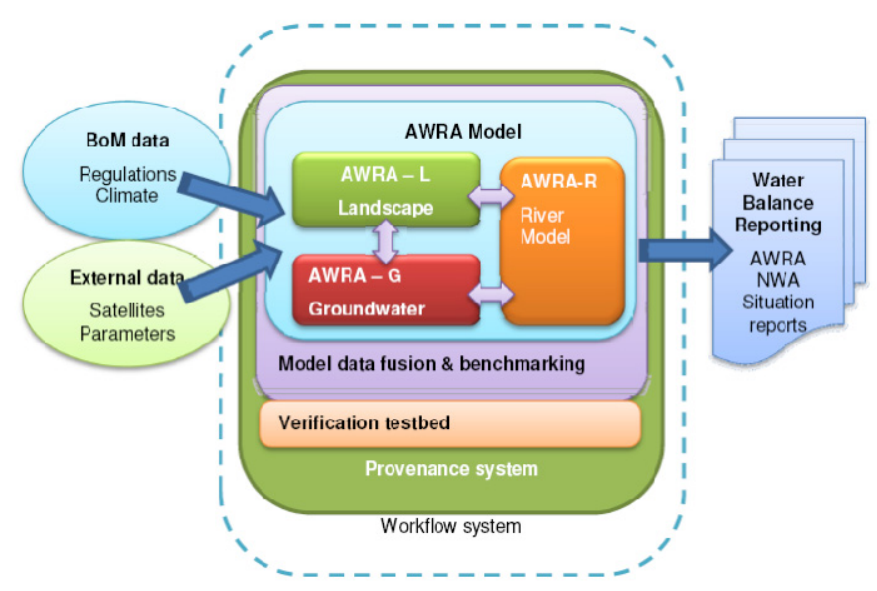

Figure 1. The AWRA modelling system. observational data wherever possible. In particular, there has been significant research and development effort on the assimilation of remotely sensed data to constrain the model and provide estimates of uncertainty in model outputs. Similarly, there has been dedicated effort in integration of the model components in a coherent framework (i.e. the AWRA modelling system, Figure 1) such that the integrated research system in CSIRO is readily transferable to, and implemented in, the operational environment at the Bureau.

The AWRA system uses available observations and an integrated landscape- groundwater-river water balance model to estimate the stores and fluxes of the water balance required for reporting purposes. This constitutes a unique example of implementing a coupled landscape, groundwater and regulated river system model at a continental scale and rolled out at high priority regions (National Water Account (NWA) regions). The Bureau has used the AWRA modelling system to undertake water resource assessments across the country and already published one Water Resource Assessment (2010) and two National Water Accounts $(2010,2011)$. There has been a steady and continuous extension and improvement in the AWRA model performance and the Bureau is currently undertaking the next round of Water Resource Assessments (2012) and a National Water Account (2012) using the latest version of the AWRA system (version 3.0). These early reports provide a clear perspective on current capabilities and operational needs of the AWRA modelling system.

This paper provides an overview of the AWRA modelling system and demonstrates its applicability by presenting key results of AWRA implementation at a continental and river basin scales. It is anticipated that forecasting water resource availability will eventually come into scope in the next three years when the retrospective components of the system are fully implemented and operating efficiently and effectively. 


\section{THE AWRA SYSTEM COMPONENTS}

\subsection{AWRA-LG (Landscape and groundwater)}

AWRA-L, the landscape component of the AWRA system, is a daily grid-based biophysical model of the water balance between the atmosphere, the soil, groundwater and surface water stores. The model aims to produce interpretable water balance component estimates, so that they agree as much as possible with water balance observations, including point gauging data and satellite observations. The model is intended to be parsimonious rather than comprehensive, appropriate to the needs of the AWRA and NWA reporting. AWRA-L currently includes descriptions of the following stores, fluxes and processes (equations and their justification are described in model documentation, van Dijk, 2010, Figure 2):

- partitioning of precipitation between interception evaporation and net precipitation,

- partitioning of net precipitation between infiltration, infiltration excess surface runoff, and saturation excess runoff,

- surface topsoil water balance, including infiltration, drainage and soil water evaporation,

- shallow soil water balance, including incoming and exiting soil drainage and root water uptake,

- deep soil water balance - same as above,

- groundwater dynamics, including recharge, capillary rise and discharge, and

- surface water body dynamics, including inflows from runoff and discharge, open water evaporation and catchment water yield.

In addition, the following vegetation processes are described:

- transpiration, as a function of maximum root water uptake and optimum transpiration rate, and

- vegetation cover adjustment, in response to the difference between a actual and a theoretical optimum transpiration, and at a rate corresponding to vegetation cover type.

AWRA-G, the groundwater component of the AWRA system, is designed to run at a continental scale but be simple enough that run times are not prohibitive. AWRA-G has one (unconfined aquifer) or two (unconfined and confined aquifers) groundwater stores and it shares water table from the unconfined aquifer with AWRA-L. It has been designed to simulate the groundwater processes to provide exchange of fluxes between AWRA-L and AWRA$\mathrm{R}$ to close the overall water balance. It includes the following groundwater processes:

- Groundwater extraction (pumping, also injection if significant),

- Lateral groundwater flow between AWRA-L cells in regional groundwater systems,

- Distribution of river losses to groundwater (from AWRA-R),

- Recharge from overbank flooding,

- Groundwater discharge to the ocean, and

- Interactions between deep confined systems and shallow groundwater systems.

\subsection{AWRA-R (regulated river system)}

AWRA-R, the river system component of the AWRA system, is a conceptual hydrological model designed for both regulated and unregulated river systems (Lerat et al., 2013a). A river system is schematised into a simplified river network using a node-link structure (Figure 3). The river network begins and ends with a node, and all nodes are interconnected by links. Runoff from gauged or ungauged tributaries or local contributing area between two nodes is fed into the connecting link as an inflow at the relevant location and all other physical processes (such as diversions, groundwater fluxes, overbank flow) occurring between the two nodes are incorporated in the model. A link is used for transfer of flow between two nodes with or without routing and transformation. The model includes six components: 1) rainfall-runoff response, 2) routing scheme, 3) irrigation modelling, 4) river-groundwater interaction component, 5) storages and 6) floodplain modelling. Daily diversion is estimated using a newly developed simplified irrigation model (Hughes et al., 2013), overbank flow and floodplain fluxes and stores are estimated using two simplified 
inundation modelling approaches (Dutta et al., 2013; Teng et al., 2013) and flux from river to groundwater is estimated using a two parameter Monod/asymptotic function (Lerat et al., 2013b).

\subsection{Model calibration procedure}

All the three AWRA components are conceptual models that include a number of parameters whose values are not known a priori. These parameter values need to be obtained through calibration. The calibration process seeks to find the set of parameters that gives the best concordance between model predictions and observed data. For AWRA-L, this is done using an automated optimisation algorithm called shuffled complex evolution. A total of seventeen model parameters are optimised for the two hydrological response units (HRUs). The model is currently calibrated at a lumped catchment scale but the calibration system is built such that it provides the option to undertake a fully gridded calibration. The optimiser seeks to maximise a mathematical function that describes the level of agreement between predicted and observed time series of streamflow and leaf area index (LAI). Streamflow and LAI data from 607 catchments spread across Australia are currently used. The

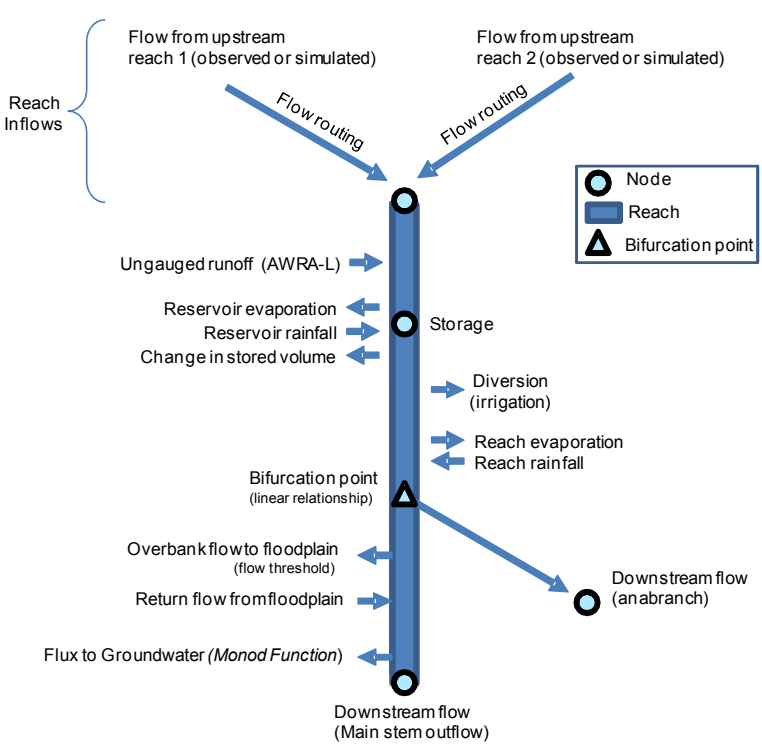

Figure 3. A conceptual representation of a river reach within AWRA-R

objective is to find a single set of continentally applicable model parameters that best facilitates model predictions of streamflow and LAI in all catchments. The calibration system has been implemented in a modular and extensible workflow tool using Microsoft Trident. AWRA-R is calibrated in a stepwise sequence using the auto-calibration procedure. Gridded surface runoff generated by AWRA-L are used to estimate runoff from ungauged headwater catchments and ungauged area along each AWRA-R reach.

\subsection{AWRA system architecture}

The architecture of the AWRA system is comprised of a three step modelling workflow (pre-process, model, post-process). This is executed by a workflow engine, which also handles ingestion of data streams and publication of outputs (Stenson et al, 2011). The modelling section of the AWRA system has three main components (Figure 4), each of which is a container for models, configuration files, data streams and model-data fusion techniques.

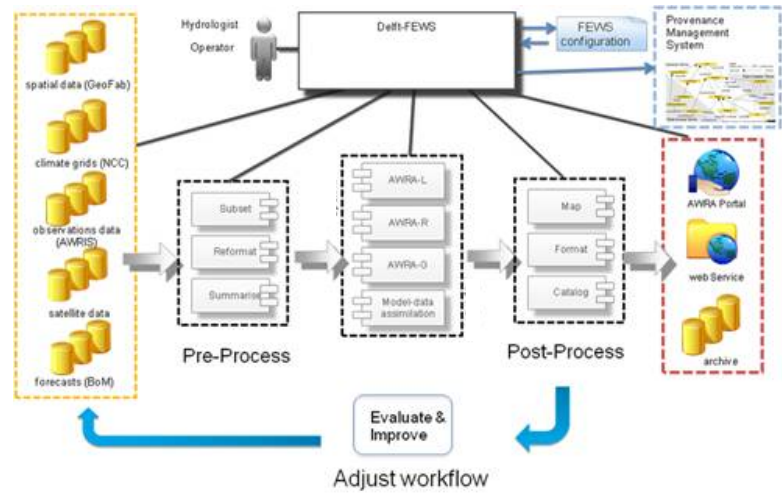

\section{AWRA IMPLEMENTATION}

Figure 4. Architecture of the AWRA modelling system.

AWRA-L v3.0 is implemented as a globally-calibrated model. That is, its Australia-wide streamflow predictions are generated using a single set of model parameters. These parameters are obtained by finding the best fit to streamflow in a set of 302 gauged calibration catchments. Model predictions are then evaluated by applying this global parameter set in an independent set of 305 gauged validation catchments (Figure 5). The current version of AWRA-R v3.0 has

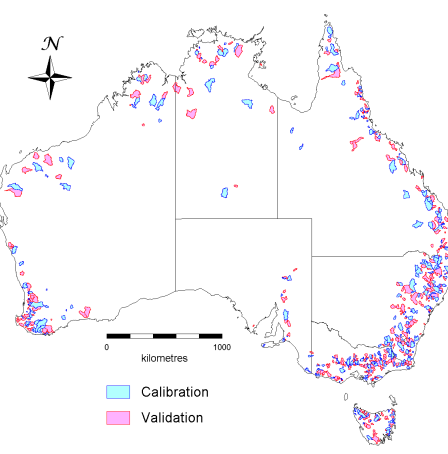

Figure 5. Distribution of calibration and validation catchments.

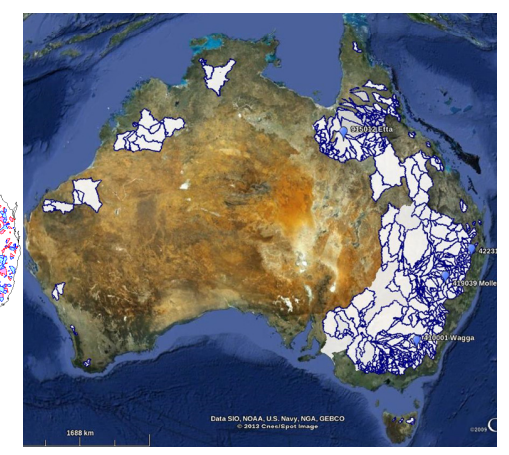

Figure 6. Map of the catchments where AWRA-R has been implemented. 
been applied in 39 catchments across Australia covering 574 reaches and 628 gauging stations (Figure 6). Here, we present a few key results to demonstrate the performance of the models. The detailed results and performance statistics of the two models are presented in Viney et al., 2013a and Lerat et al., 2013b.

\subsection{AWRA-L}

Figure 7 shows the cumulative distribution of monthly model efficiency and absolute bias for calibration and validation for AWRA-L, Sacramento and GR4J models. For each value of the metric (the y-axis), the non-exceedance probability ( $\mathrm{x}$ axis) shows the proportion of catchments with a lower metric value. Better models are shown by higher nonexceedance curves for the efficiency metrics and for bias, the better models have lower non-exceedance curves of absolute bias values that are closer to zero.

The results show that in both calibration and validation, AWRA-L typically provides streamflow predictions that are as good as the alternatives. Furthermore, it does not suffer from some of the peer models' drawbacks such as spatial discontinuities in streamflow generation and performance deterioration with increasing

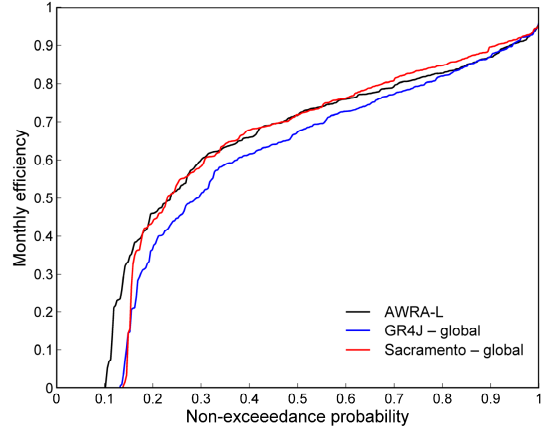

a) Monthly calibration efficiency

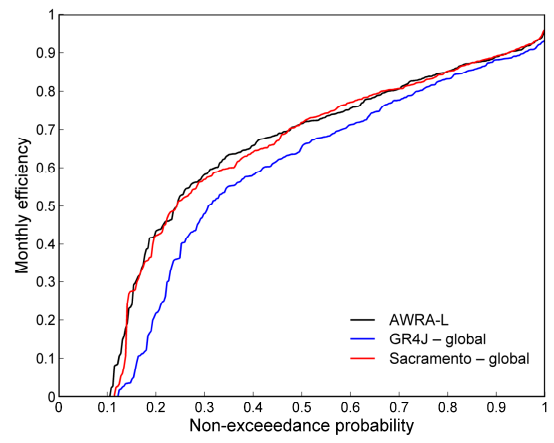

c) Monthly validation efficiency

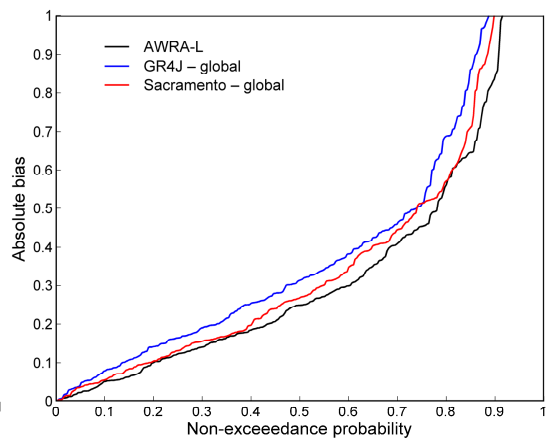

b) Absolute bias in calibration

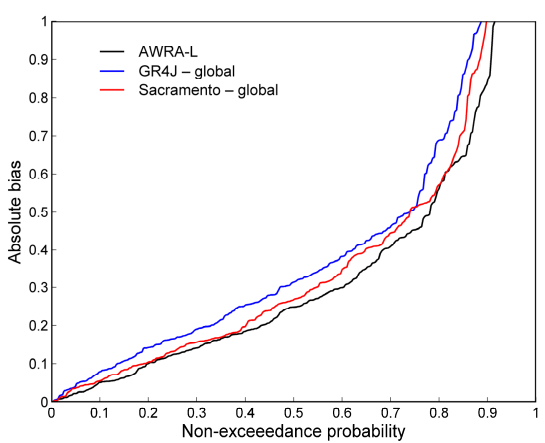

d) Absolute bias in validation
Figure 7: Cumulative distribution of (a) calibration and (c) validation monthly efficiency and (b) calibration and (d) validation absolute bias of streamflow predictions by AWRA-L and two globally-calibrated models. regionalisation distances (Viney et al., 2013b). AWRA has also been developed to specifically predict stores and fluxes other than streamflow, and has been explicitly coupled to groundwater and river system modules. This is particularly important for semi-automated delivery of water accounts and periodic national water resources assessments.

\subsection{AWRA-R}

Figure 8 compares the simulated inundation extents and depths by AWRA-R with the results of MIKE21 2D hydrodynamic (HD) model in a floodplain reach in Murrumbidgee. It shows AWRA-R results agree well with the HD model. Figures 9 and 10 provide examples of AWRA-R simulated daily time series of floodplain and irrigation fluxes and stores, respectively. These are required for closing the river water balance and for producing NWA reporting items. Figure 11 presents the performance statistics (monthly NSE and absolute bias) of streamflow predictions by AWRA-

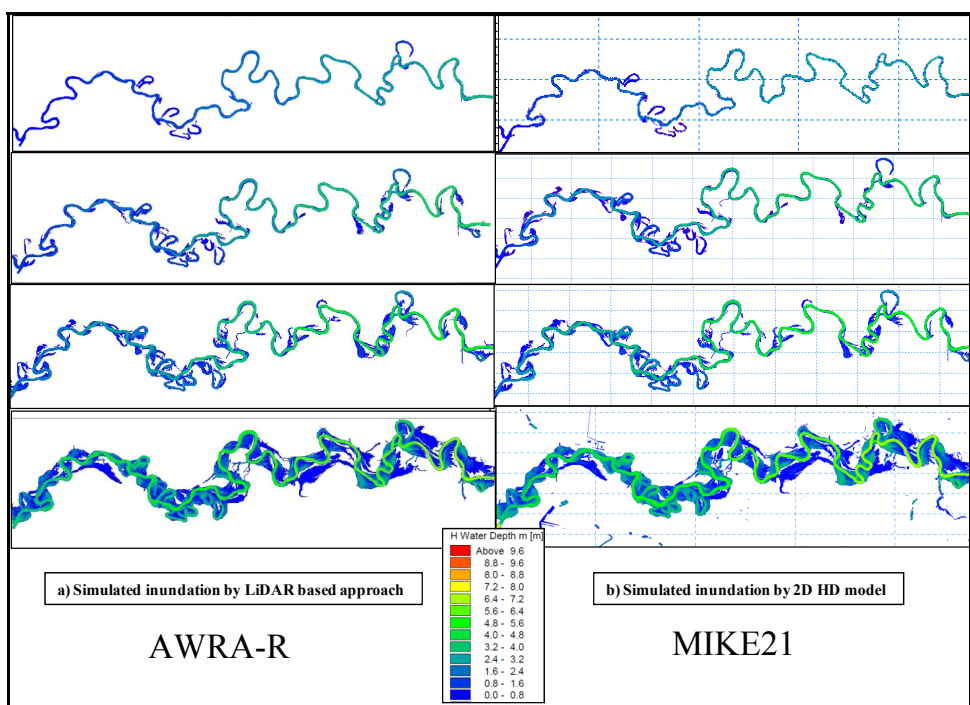

Figure 8: Snapshots of inundation extent and depth variations between gauges 410002-410136 simulated by: a) AWRA-R and b) MIKE21 on four different days during a flood event of 2012. 
$\mathrm{R}$ in the headwater and lower reaches of the different modelling regions. The performance of the model is highly satisfactory with median monthly NSE above 0.6 and absolute bias less than $20 \%$ in the headwater and lower reaches of most of the modelling regions.

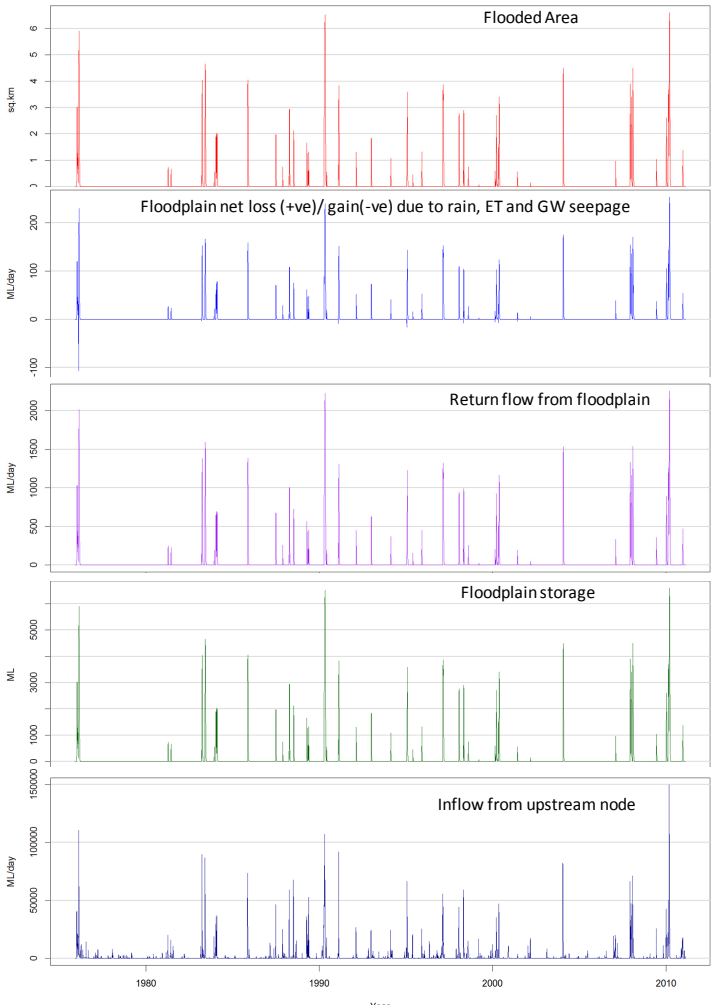

Figure 9: Daily time series floodplain fluxes for two floodplain reaches in Paroo.
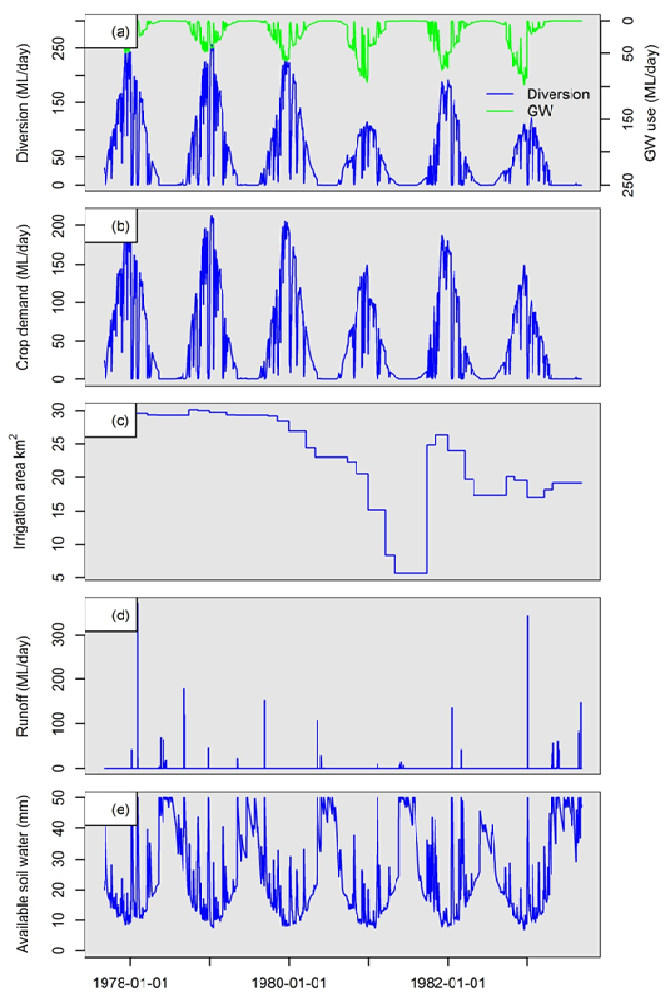

Figure 10: Irrigation fluxes from the AWRA-R irrigation model for a district in the Namoi valley.

\section{DISCUSSION AND CONCLUSIONS}

The AWRA system uses available observations and an integrated landscape-groundwaterriver water balance model to estimate the stores and fluxes of the water balance required for continental scale reporting purposes. This constitutes a unique example of implementing a coupled landscape, groundwater and regulated river system model at a continental scale and rolled out at high priority regions (NWA regions).

The results for AWRAL implementation across 607 gauged catchments show that in both

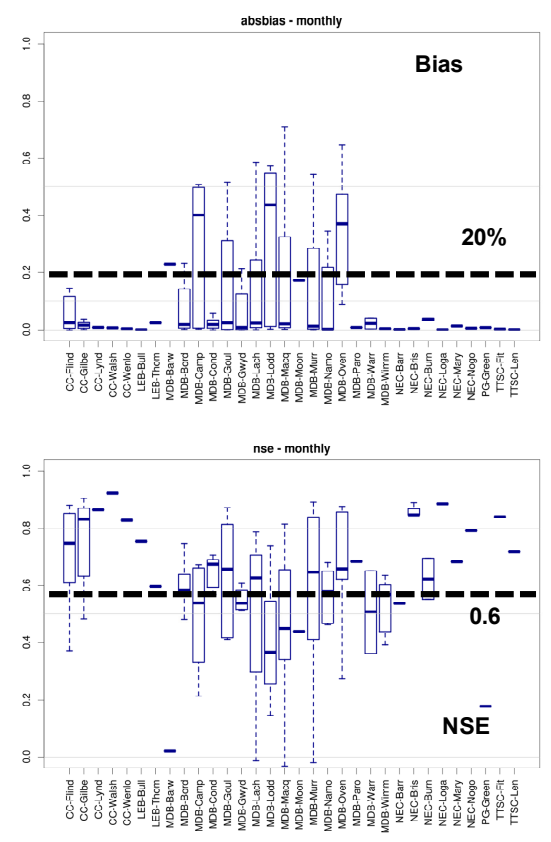

a) Headwater reaches
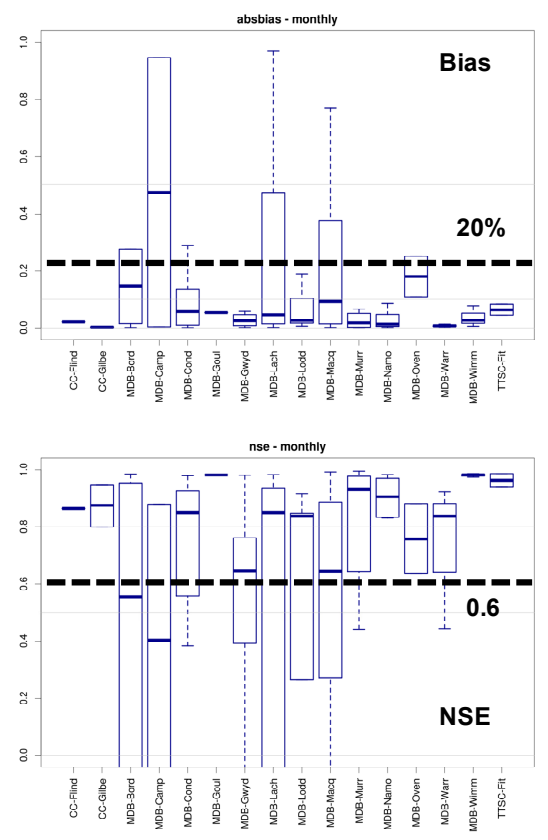

b) Lower reaches
Figure 11: Monthly performance statistics of AWRA-R model in headwater and lower reaches of different modelling regions 
calibration and validation, the model typically provides streamflow predictions that are similar to those from other widely used conceptual hydrological models. AWRA has also been developed to specifically predict stores and fluxes other than streamflow, and has been explicitly coupled to groundwater and river system modules. This is particularly important for semi-automated delivery of water accounts and periodic national water resources assessments.

The AWRA-R model includes newly developed components for floodplain inundation modelling, accounting for irrigation diversions and groundwater surface water interactions. The results show that the model performs well in majority of the modelling regions and it provides all the water fluxes and stores required for NWA.

The software architecture developed as part of AWRA integrates the individual components in a seamless manner with transfer of fluxes between the components at a daily time step for operational implementation. The system is fully functional on the Bureau's operational infrastructure. The Bureau has used the AWRA modelling system to undertake water resource assessments across the country and already published one Water Resource Assessment (2010) and two National Water Accounts (2010, 2011). There has been a steady and continuous extension and improvement in the AWRA model performance and the Bureau is currently undertaking the next round of Water Resource Assessments (2012) and a National Water Account (2012) using the current version of the AWRA system. It is anticipated that what-if scenario modelling and forecasting water resource availability will eventually come into scope in the next three years when the retrospective components of the system are fully implemented and operating efficiently and effectively.

\section{ACKNOWLEDGMENTS}

This work is carried out in the Water for a Healthy Country Flagship, CSIRO and is funded by the WIRADA research alliance between the Bureau of Meteorology and the CSIRO.

\section{REFERENCES}

Dutta, D., Teng, J., Vaze, J., Hughes, J., Lerat, J., and Marvanek, S. (2013). Building Flood Inundation Modelling Capability in River System Models for Water Resources Planning and Accounting, In: Climate and land surface changes in hydrology, IAHS Red Book (ed by Boegh et al.), IAHS Publication, 205-212.

Hughes, J., Mainuddin, M., Lerat, J., and Dutta, D. (2013). An irrigation model for use in river systems modelling, Proceedings of the $20^{\text {th }}$ International Congress on Modelling and Simulation, Adelaide, Australia, 2013 (in press).

Lerat, J., Dutta, D., Kim, S., Hughes, J., and Vaze, J. (2013a). Reducing propagation of uncertainty in river system modelling by optimal use of streamflow data. Proceedings of the $20^{\text {th }}$ International Congress on Modelling and Simulation, Adelaide, Australia, 2013 (in press).

Lerat, J., Dutta, D., Kim, S., Hughes, J., Vaze, J., and Dawes, W. (2013b). Refinement and extension of the AWRA-R model, CSIRO: Water for a Healthy Country National Research Flagship.

Stenson, M. P., Fitch, P., Vleeshouwer, J., Frost, A. J., Bai, Q., Lerat, J., Leighton, B., Knapp, S., Warren, G., Van Dijk, AIJM., Bacon, D., Pena Arancibia, J. L., Manser, P., and Shoesmith, J. (2011). Operationalising the Australian Water Resources Assessment system, In Proceedings, Water Information Research and Development Alliance Science Symposium. Pages 36-45.

Teng J., Vaze, J., and Dutta, D. (2013). Simplified methodology for floodplain inundation modelling using LiDAR DEM, In: Climate and land surface changes in hydrology, IAHS Red Book (ed by Boegh et al.), IAHS Publication, 198-204.

Van Dijk, AIJM. (2010). The Australian Water Resources Assessment System. Technical Report 3. Landscape Model (version 0.5) Technical Description. CSIRO: Water for a Healthy Country National Research Flagship.

Viney, N. R., and Vaze, J. (2013b). Influence of regionalisation distance on nearest-neighbour regionalization. Proceedings of the $20^{\text {th }}$ International Congress on Modelling and Simulation, Adelaide, Australia, 2013 (in press).

Viney, N. R., Vaze, J., Wang, B., Zhang, Y., Yang, A., Vleeshouwer, J., Ramchurn, A., and Frost, A. (2013a). Comparison of prediction performance of AWRA-L with other models. CSIRO: Water for a Healthy Country National Research Flagship. 